\title{
A Case of the Vibrant Soundbridge Implantation to Unilateral Congenital Aural Atresia
}

\author{
Young Sang Cho, Ji Eun Choi, and Yang-Sun Cho \\ Department of Otorhinolaryngology-Head and Neck Surgery, Samsung Medical Center, Sungkyunkwan University School of Medicine, \\ Seoul, Korea
}

선천성 외이도 폐쇄증 환자에서의 중이 이식술 1예

조영상 · 최지은 · 조양선

성균관대학교 의과대학 삼성서울병원 이비인후과학교실

\author{
Received February 2, 2016 \\ Revised April 8, 2016 \\ Accepted April 15, 2016 \\ Address for correspondence \\ Yang-Sun Cho, MD, PhD \\ Department of Otorhinolaryngology- \\ Head and Neck Surgery, \\ Samsung Medical Center, \\ Sungkyunkwan University \\ School of Medicine, \\ 81 Irwon-ro, Gangnam-gu, \\ Seoul 06351, Korea \\ Tel $+82-2-3410-3578$ \\ Fax $+82-2-3410-3879$ \\ E-mail yangsun.cho@gmail.com
}

Middle ear implantation is indicted for patients who have sensorineural, conductive or mixed hearing loss when conventional surgery or hearing aids do not producde sufficient improvement. This study reports the long-term results of an active middle ear implant, the Vibrant Soundbridge ${ }^{\circledR}$ (VSB) implantation, in a patient with unilateral congenital aural atresia (CAA). VSB was implanted for hearing rehabilitation after failed canaloplasty in a 15-year-old girl. After exposure of deformed ossicle, the floating mass tranceducer was coupled to the stapes head and subsequent subtotal petrosectomy was completed. Preoperative pure-tone air conduction threshold was $68.8 \mathrm{~dB}$, which improved to $15 \mathrm{~dB}$ at one year of surgery. The mean aided free field speech discrimination in quiet was $98 \%$. The speech understanding in noise evaluated by the composite score of Hearing-In-Noise test improved from SNR $-2.5 \mathrm{~dB}$ to $-5.2 \mathrm{~dB}$. We present a first report of VSB implantation in a patient with unilateral CAA in Korea. The patient showed a significant hearing gain after the implantation of VSB; moreover, her hearing in noisy environment also showed improvement.

Korean J Otorhinolaryngol-Head Neck Surg 2017;60(8):411-5

\section{서 론}

선천성 외이도 폐쇄증은 이개 및 중이의 기형과 연관되어 있 으며 종종 내이의 기형과도 관련되어 있다. 유병률은 1:10000 에서 1:20000 정도로 편측성이 대부분이며 남성이 여성보다 2.5배 정도 많은 것으로 보고되고 있다. ${ }^{1)}$ 선천성 외이도 폐쇄 증을 가진 대부분의 환자들은 중고도에서 고도의 전음성 난 청을 보이며 특히 양측에 기형을 가지고 있으면 유아기 때부 터 심각한 언어발달 지연을 가져 올 수 있다. ${ }^{2)}$ 한쪽에만 폐쇄

This is an Open Access article distributed under the terms of the Creative Commons Attribution Non-Commercial License (http://creativecommons.org/licenses/by-nc/4.0) which permits unrestricted non-commercial use, distribution, and reproduction in any medium, provided the original work is properly cited.
증을 가지고 있으면 언어발달은 정상을 보이나 소리에 대한 방향 감각이 떨어지며 학습활동이나 의사소통에 문제가 있 을 수 있다. ${ }^{3)}$ 또한 한쪽의 외이도 폐쇄증 환자들은 심리적으 로 자존감이 떨어져 있고, 지능지수(intelligence quotient)도 정상인들보다 유의하게 낮다는 보고도 있어 ${ }^{4)}$ 최근에는 한쪽 에 국한된 선천성 외이도 폐쇄증이라 하더라도 적극적인 치 료를 고려하는 추세이다.

선천성 외이도 폐쇄증의 치료에는 비침습적으로는 골 전도 보청기를 착용하는 방법이 있고, 침습적으로는 외이도 성형 술을 시행하거나 이식형 보청기를 삽입하는 방법이 있다. 최 근까지도 한쪽의 외이도 폐쇄증의 치료에 대해서는 이견이 있 지만 외이도 성형술 후 소리의 방향성이 향상되고, 소음환경 
에서 어음명료도가 증가하며, 이는 곧 청소년기의 학습 능력 의 증대와 연결될 수 있으므로 적극적인 치료가 필요하다. 치 료 방법으로는 외이도 성형술이 8 10세 이상의 소아에서 시행 됐으나, 최근 들어 이식형 보청기의 개발 및 발전으로 선천성 외이도 폐쇄증에서 Bone-Anchored Hearing Aid ${ }^{\circledR}$ (BAHA; Cochlear Corporation, Sydney, Australia), Bonebridge ${ }^{\circledR}(\mathrm{BB}$; MedEl Company, Innsbruck, Austria) 등의 골 전도 이식형 보청기와 Vibrant Soundbridge ${ }^{\circledR}$ (VSB; MedEl Company) 등을 이용하여 적은 합병증으로 유의한 청력 개선을 거둔 결 과들이 보고되고 있다. ${ }^{5)}$

1993년 floating mass transducer(FMT)가 개발된 후 VSB 는 혼합성 난청 및 전음성 난청에서 사용되고 있는데, 국내에 서는 2011년 최초의 중이 이식 수술이 소개된 이후 외이도 폐 쇄증을 가진 환자에서 1년 이상 경과관찰을 한 예는 아직 보 고된 바 없다. 저자들은 한쪽의 소이증과 외이도 폐쇄증을 가 진 15세 여아에서 VSB를 이용한 중이 이식술을 시행하고 1년

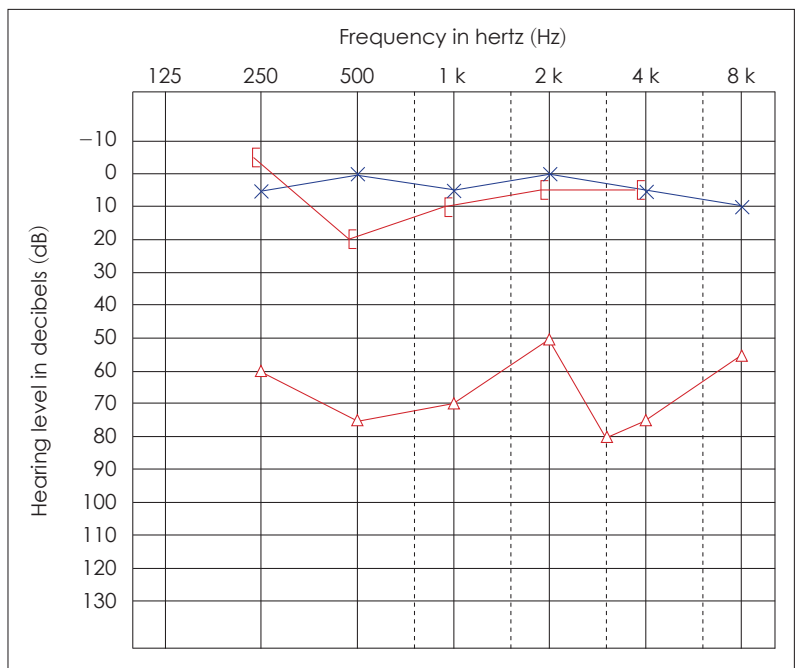

Fig. 1. Preoperative pure tone audiogram shows a moderately severe unilateral conductive hearing loss.
간의 추적관찰을 통해 우수한 청력 개선 효과를 얻은 증례를 문헌 고찰과 함께 보고하는 바이다.

\section{증 례}

우측의 소이증과 선천성 외이도 폐쇄증으로 5년 전에 늑연 골을 이용한 외이 재건술을 시행한 13 세 여아에서 1년 전에 외이도 성형술을 시도하였으나 이개의 위치가 너무 전방에 위 치하여 외이도 재건을 통해 청력이 호전되지 않았다. 좌측 청 력은 정상이었으며 이학적 검진에서 좌측의 외이도 및 고막은 정상 소견이었다. 순음청력검사 $(500,1000,2000,3000 \mathrm{~Hz}, 4$ 분법)상 골도/기도 청력역치는 우측 $10.0 / 68.8 \mathrm{~dB}$, 좌측 2.5/ $2.5 \mathrm{~dB}$ 로 우측의 전음성 난청 소견이었으며, 어음명료도 검사 는 우측 $96 \%$, 좌측은 $100 \%$ 였다(Fig. 1). 측두골 컴퓨터단층 촬영검사(temporal bone computed tomography, TBCT)에 서 우측의 외이도 폐쇄증과 함께 이소골의 이형성 소견을 보 였으며, Jahrsdoerfer 점수는 중이구조와 안면신경의 주행에

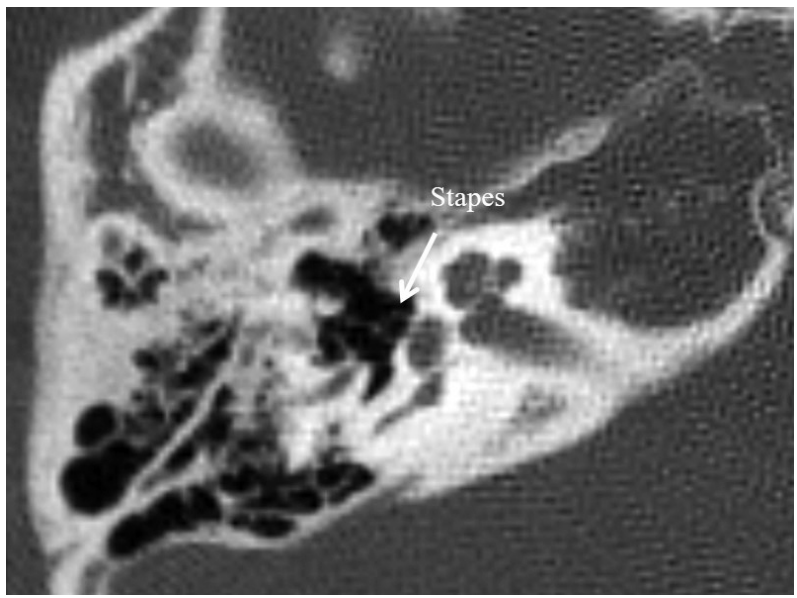

Fig. 2. Bony atresia of right external auditory canal, dysplastic malleus-incus complex and stapes structure are observed in preoperative computed tomography scan.
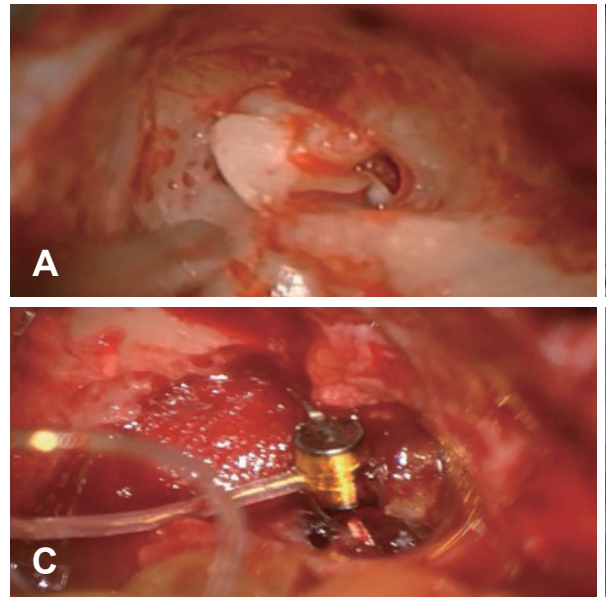
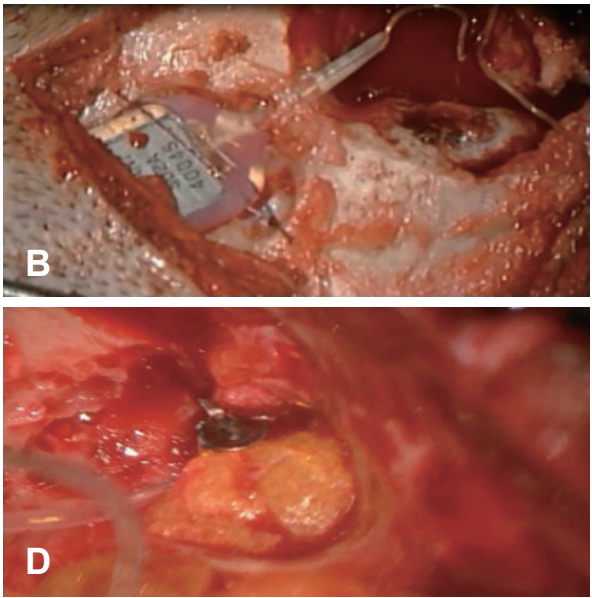

Fig. 3. Right vibroplasty. Malleus-Incus complex was removed after IS joint separation (A). Placing a VORP into the pre-made well $(B)$. Coupling of FMT to the stapes head (C). Eustachian tube obliteration and filling of cavity with abdominal fat (D). VORP: vibrating ossicular prosthesis, FMT: floating mass transducer. 


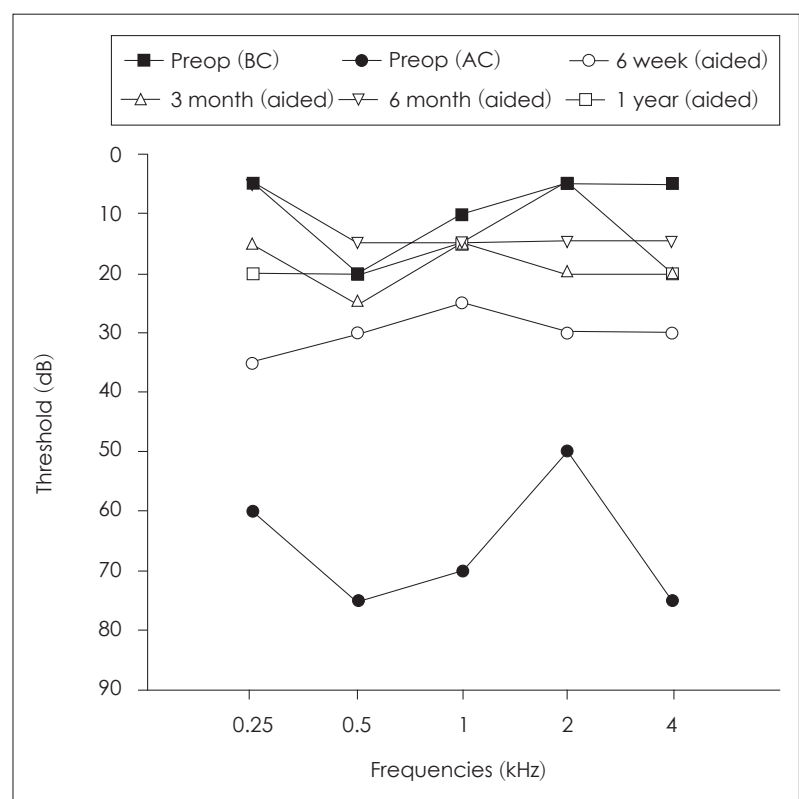

Fig. 4. Postoperative aided pure tone audiogram. The line marked with back dot shows right aided hearing level at 6 weeks after operation. After 3 months, right aided hearing threshold improved to $18.8 \mathrm{~dB}$. Audiogram at 6 months after operation shows a further improved threshold of $15 \mathrm{~dB}$, which was maintained to postoperative 1 year.

는 심한 기형이 없었으며 외이의 모양에서 1점 감점되어 9점 으로 평가되었다(Fig. 2).

환자는 우측의 고도 난청으로 인해 학습 시 불편을 호소하 였으며, 청력재활을 위해 VSB이식수술을 시행하였다. 수술 은 후이개 절개를 한 후 안면신경 감시장치를 유지하면서 유 양동삭개술을 시행하여 이형성이 있는 이소골에 접근하였다. 그 후 유양동의 후방으로 드릴을 이용하여 두개골에 내부장 치를 위치시키기 위한 자리를 만들었다. 추침골 복합체를 제 거한 뒤 기존에 부착되어 있는 FMT의 클립을 제거하고, Stapes coupler를 FMT에 연결하고, 이를 등골 두부에 진동 축과 평행하게 위치시켰다. 이어서 이관을 폐쇄하고 복부의 지방으로 수술 공간을 채워 추체아전삭개술을 마쳤으며(Fig. 3), 수술 중 특별한 합병증은 없었다. 수술 6주 경과 후 외부장 치를 조절하고 정상청력을 가진 좌측을 차폐 한 뒤 진음(warble tone)을 이용하여 음장청력검사(sound field audiometry) 를 시행한 결과, 우측 기도청력 역치는 $28.8 \mathrm{~dB}$ 로 수술 전에 비해서 $40 \mathrm{~dB}$ 이 호전되었다(Fig. 4). 이때 음질에 대해서는 선명하지만 기계음처럼 자연스럽지 않은 음으로 들린다고 표 현하였으며 약간의 자가강청이 동반 된다고 기술하였다. 수 술 후 3개월째 TBCT를 통해 이식한 FMT가 중이강 내 잘 위 치하고 있음을 확인하였고(Fig. 5), 음장청력검사상 기도청력 역치 $18.8 \mathrm{~dB}$ 로 소리는 좀 더 명료해지고 골도청력 역치는 10 $\mathrm{dB}$ 로 술 전과 변화가 없었다(Fig. 4).
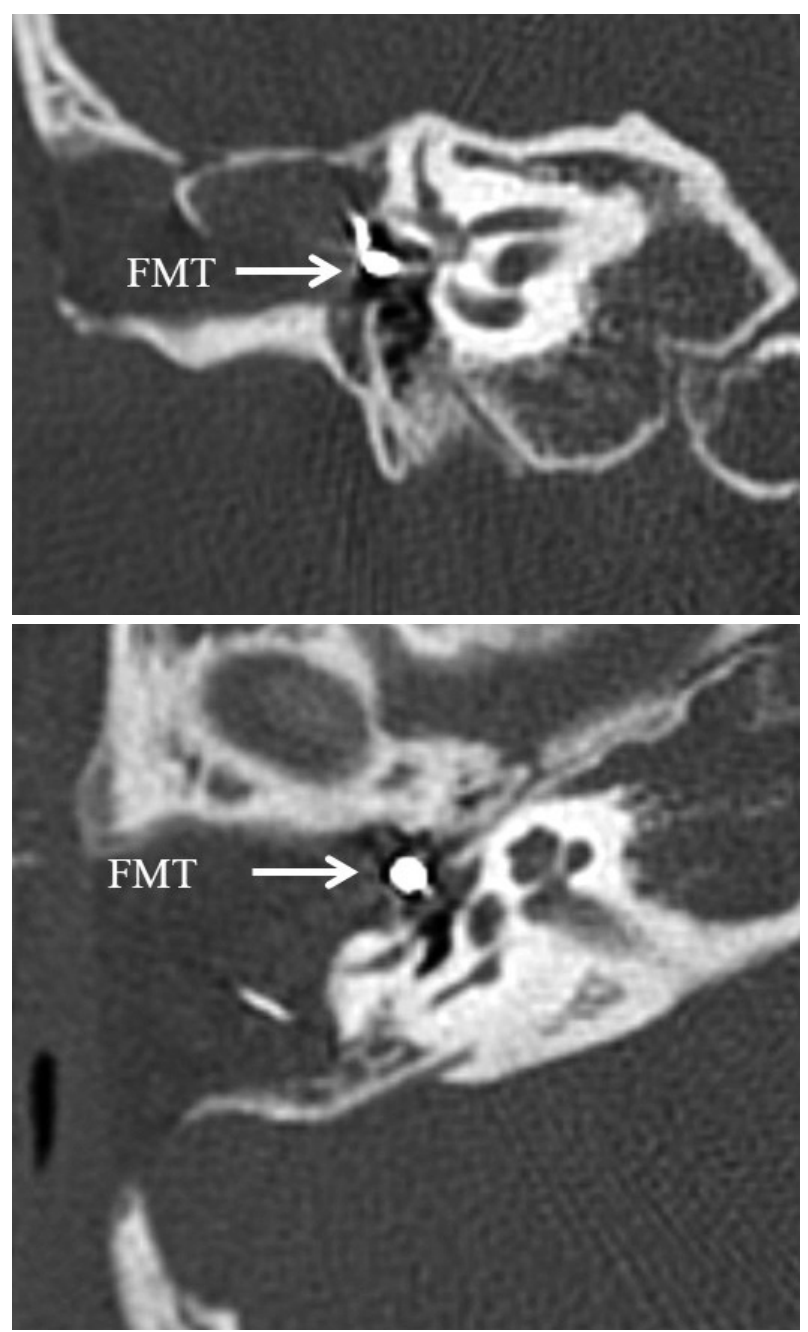

Fig. 5. Postoperative temporal bone computed tomography. Coronal and axial image show that FMT is placed on the stapes. FMT: floating mass transducer.

Table 1. Pre- and postoperative hearing in noise test results

\begin{tabular}{lcc}
\hline & Pre OP & Post OP \\
\hline Quiet (dB A) & 27.2 & 18.9 \\
Noise front (dB S/N) & -1.7 & -2.3 \\
Noise ipsilateral (dB S/N) & -7.8 & -8.9 \\
Noise contralateral (dB S/N) & 1.4 & -7.5 \\
Noise composite $(\mathrm{dB} \mathrm{S/N)}$ & -2.5 & -5.2 \\
\hline
\end{tabular}

술 후 6개월째 시행한 음장청력검사상 기도청력 역치는 우 측 $15 \mathrm{~dB}$ 로 전 주파수 대역에서 안정적이고 수평형 청력도를 보였다(Fig. 4). Hearing-in-noise test(HINT) 결과, 정상 청력 을 가진 좌측 귀에서 소음을 주었을 때 SNR 값이 수술 전 1.4 에서 수술 후 $-7.5 \mathrm{~dB}$ 로 크게 호전되었으며 composite score 도 $-2.5 \mathrm{~dB}$ 에서 $-5.2 \mathrm{~dB}$ 로 낮아져 소음환경 속에서 들을 수 있는 어음 청취 역치가 크게 호전되었음을 확인 하였다(Table 1). 수술 후 1 년 경과 후에도 우측의 기도청력역치는 $15 \mathrm{~dB}$ 로 
유지되었으며(Fig. 5), 어음명료도 검사상 우측 98\%, 좌측 $100 \%$ 였다. 환자는 우측으로도 소리가 크게 들려 청력에 대 한 만족도는 높으나, 전자기기 옆으로 지나가면 '윙' 하는 기 계음이 한 번씩 들리는 것에 불편함을 호소하였다.

\section{고 찰}

선천성 외이도 폐쇄증 환자에게서의 수술적 치료에 대해 최근 35년 동안 다양한 수술적 기법들이 발전하고 성공률이 높아졌지만, 아직 청력 개선의 효과는 기대만큼 높지 않으 며, ${ }^{6}$ 술 후 외이도 재협착 및 염증을 방지하기 위한 지속적인 관리가 필요하다. 수술이 성공적일 경우 술 후 어음수용 역치 는 평균 25 35 dB 정도이며, 양측에 이환된 환자 중 30\% 정 도는 추가적인 보청기 사용이 필요하다고 보고되었다. 술 후 재협착이 일어나는 빈도는 5 29\% 정도이며 이 중 26\% 정도 의 환자는 재수술이 필요하고," 수술 이후 ear mold나 보청기 를 착용하는 것이 재협착을 방지하는 데 도움이 된다. ${ }^{8}$ 또한 수술 후 안면신경의 마비가 발생하는 빈도는 $1 \%$ 부터 $30 \%$ 까 지 보고되고 있다. ${ }^{9}$

이러한 외이도성형술의 제한점으로 인해 최근에 소개된 이 식형 보청기(BAHA, BB, VSB)들이 주목을 받고 있으며 이들 은 높은 청력 개선 효과와 상대적으로 낮은 합병증이 보고되 고 있다. ${ }^{10}$

$\mathrm{BAHA}$ 나 $\mathrm{BB}$ 는 $\mathrm{CAA}$ 환자들에서 수술 후 기도골도차(airbone gap)가 $80 \%$ 이상에서 $10 \mathrm{~dB}$ 이하로 줄고 평균 이득 $35.2 \mathrm{~dB}$ 의 우수한 청각적 결과를 보이고 있다. BAHA의 경 우 연부조직 합병증이나 골유착이 실패하는 경우가 종종 보 고 되고 있지만 최근 들어 피부 관통 방식 대신 경피적으로 부착할수 있는 방법이 개발되면서 연부조직 합병증은 많이 해결되었다.9 하지만 이와 같은 골전도 이식형 보청기의 경우 청력 개선 효과는 외이도 성형술에 비해 높으나 소리의 방향 성이나 소음환경에서의 어음 명료도를 개선시키지 못한다는 단점이 있다. 최근 연구에서 편측의 난청 환자에서 BAHA가 소리 방향성 검사(sound localization test)나 HINT에서 제한 된 이득을 보여주었으며, 이는 BAHA를 사용하지 않았을 때 와 유의한 차이를 보여주지 못하였다. ${ }^{11,12}$

VSB는 외부의 sound processor로부터 수집된 소리 신호가 중이 강에 위치한 $\mathrm{FMT}$ 에 전달되어 진동으로 변환, 연결된 이소골이나 난원창, 정원창 등에 직접 소리를 전달한다는 점 에서 $\mathrm{BAHA}$ 나 $\mathrm{BB}$ 와 소리 전달 방식이 다르다. 따라서 $\mathrm{VSB}$ 는 골전도 보청기와는 달리 양이 청을 가능하게 하여 소리의 방향성과 소음 환경 아래서 어음명료도를 호전시킬 수 있다. 본 증례에서도 HINT검사에서 composite 점수가 $-2.5 \mathrm{~dB}$ 에
서 $-5.2 \mathrm{~dB}$ 로 크게 호전되는 것을 관찰할 수 있었고 이는 대 부분 소음이 정상 측에서 들어올 때 신호 대 잡음 비가 호전 되는 것의 영향이 컸다(Fig. 4). 또한 $\mathrm{VSB}$ 는 나이에 상관없이 수술할 수 있다는 장점도 있으며, ${ }^{13)}$ 청력 이득은 기도청력에 서 평균 $45.5 \mathrm{~dB}$ 부터 $55.1 \mathrm{~dB}$ 까지도 보고되고 있다. ${ }^{14)}$

본 증례에서는 선천성 외이도 폐쇄증 환자에서 FMT를 등 골 두부에 이식하였고 수술 6주 후 외부 장치를 부착하여 현 재 1 년째까지 경과관찰 중이며, 음장 청력검사에서 기도골도 차는 $58.8 \mathrm{~dB}$ 에서 $7.5 \mathrm{~dB}$ 로 호전되었으며 전 주파수에서 현 저한 청력 이득을 관찰할 수 있었다. 수술 후 6개월째까지는 기도 청력이 서서히 호전되었는데, 이는 FMT가 완전히 고정 되고 안정화 되는데 필요한 기간으로 생각되며, ${ }^{13)}$ 술 후 6개월 째 부터는 큰 변동 없이 안정적으로 청력이 유지됨을 관찰할 수 있었다. 외이도 성형술을 시행한 다른 환자들에 비해 귓 구멍이 만들어지지 않아서 외형적인 불이익이 있을 수 있고 향후 자기공명 영상 촬영이 제한되고, 전자기기 근처에서는 잡 음이 발생하는 등 문제점이 있지만 그럼에도 불구하고 생애 주기 중에 언어 발달시기에 적절한 청각 재활로서의 중이 이 식은 나머지 생애 동안 삶의 질을 향상시킬 수 있다.

Frenzel 등 ${ }^{13)}$ 은 외이도 폐쇄증을 가진 환자에서 고전적인 외 이도 성형술을 시행하였을 경우 미국 이비인후과 학회(AAO$\mathrm{HNS}$ )에서 정한 Class A 청력(순음 기도청력 역치 $<30 \mathrm{~dB}$, 어 음명료도 $>70 \%)$ 에 들어가는 경우는 평균 $40 \%$ 정도이지만, 7명의 환자에서 중이 이식술을 시행한 후 8개월간 경과관찰 한 결과 모두 Class A 청력을 얻을 수 있었으며 평균 기도 청력 이득은 $45.5 \mathrm{~dB}$ 로 중이 이식술이 외이도 폐쇄증 환자에서의 청력 개선에 상대적으로 효과가 크다고 하였다. ${ }^{15)}$

수술 후 1 년간 경과관찰 한 본 증례에서 볼 때 중이 이식 술은 기존의 기도 전도 보청기를 통한 청력 재활이 어려운 환 자들뿐만 아니라 선천성 외이도 폐쇄증을 가진 환자에게서도 장기적으로 안정적인 청력 개선 효과와 함께 소음 환경 속 어 음명료도의 획기적인 개선을 보여주어 외이도 성형술로 좋은 결과를 기대하기 힘든 환자들에게 적절한 대안으로 생각된다.

\section{REFERENCES}

1) El-Begermy MA, Mansour OI, El-Makhzangy AM, El-Gindy TS. Congenital auditory meatal atresia: a numerical review. Eur Arch Otorhinolaryngol 2009;266(4):501-6.

2) Siegert R, Mattheis S, Kasic J. Fully implantable hearing aids in patients with congenital auricular atresia. Laryngoscope 2007;117 (2):336-40.

3) Kesser BW, Krook K, Gray LC. Impact of unilateral conductive hearing loss due to aural atresia on academic performance in children. Laryngoscope 2013;123(9):2270-5.

4) Lieu JE, Tye-Murray N, Fu Q. Longitudinal study of children with unilateral hearing loss. Laryngoscope 2012;122(9):2088-95.

5) Lo JF, Tsang WS, Yu JY, Ho OY, Ku PK, Tong MC. Contemporary 
hearing rehabilitation options in patients with aural atresia. Biomed Res Int 2014;2014:761579.

6) De la Cruz A, Teufert KB. Congenital aural atresia surgery: long-term results. Otolaryngol Head Neck Surg 2003;129(1):121-7.

7) De la Cruz A, Linthicum FH Jr, Luxford WM. Congenital atresia of the external auditory canal. Laryngoscope 1985;95(4):421-7.

8) Moon IJ, Cho YS, Park J, Chung WH, Hong SH, Chang SO. Longterm stent use can prevent postoperative canal stenosis in patients with congenital aural atresia. Otolaryngol Head Neck Surg 2012;146 (4):614-20.

9) Teufert KB, De la Cruz A. Advances in congenital aural atresia surgery: effects on outcome. Otolaryngol Head Neck Surg 2004;131 (3):263-70.

10) Verhagen CV, Hol MK, Coppens-Schellekens W, Snik AF, Cremers $\mathrm{CW}$. The Baha Softband. A new treatment for young children with bilateral congenital aural atresia. Int J Pediatr Otorhinolaryngol 2008;72(10):1455-9.
11) Wazen JJ, Ghossaini SN, Spitzer JB, Kuller M. Localization by unilateral BAHA users. Otolaryngol Head Neck Surg 2005;132(6): 928-32.

12) Linstrom CJ, Silverman CA, Yu GP. Efficacy of the bone-anchored hearing aid for single-sided deafness. Laryngoscope 2009;119(4): 713-20.

13) Frenzel H, Hanke F, Beltrame M, Steffen A, Schönweiler R, Wollenberg B. Application of the Vibrant Soundbridge to unilateral osseous atresia cases. Laryngoscope 2009;119(1):67-74.

14) Zernotti ME, Arauz SL, Di Gregorio MF, Arauz SA, Tabernero P, Romero MC. Vibrant Soundbridge in congenital osseous atresia: multicenter study of 12 patients with osseous atresia. Acta Otolaryngol 2013;133(6):569-73.

15) Committee on Hearing and Equilibrium guidelines for the diagnosis and evaluation of therapy in Menière's disease. American Academy of Otolaryngology-Head and Neck Foundation, Inc. Otolaryngol Head Neck Surg 1995;113(3):181-5. 